Article

\title{
Extraction of Rare Earth Metal Ions with an Undiluted Hydrophobic Pseudoprotic Ionic Liquid
}

\author{
Michiaki Matsumoto*(D), Takuya Yamaguchi and Yoshiro Tahara \\ Department of Chemical Engineering and Materials Science, Doshisha University, Kyoto 610-0321, Japan; \\ t.yamaguchi.12321@gmail.com (T.Y.); ytahara@mail.doshisha.ac.jp (Y.T.) \\ * Correspondence: mmatsumo@mail.doshisha.ac.jp; Tel.: +81-774-65-6655
}

Received: 23 March 2020; Accepted: 9 April 2020; Published: 11 April 2020

\begin{abstract}
Recovering and concentrating rare earth metals (Nd and Dy) from waste permanent magnets rather than discarding them into the environment without pretreatment is critical for metal recycling and environmental responsibility. In this work, we used an undiluted hydrophobic pseudoprotic ionic liquid composed of trioctylamine and decanoic acid as an extractant to separate rare earth metals from aqueous media with a solvent extraction technique. This ionic liquid proved to be excellent with low viscosity and extractability reaching $100 \%$ for $\mathrm{Nd}$ and $\mathrm{Dy}$ in the presence of salts like sodium chloride and sodium nitrate. In acidic media, extractability decreased with increasing acid concentrations. Under all our experimental conditions, the rare earth metals ( $\mathrm{Nd}$ and Dy) were found to be preferentially extracted compared to nickel with the distribution ratios of Dy higher than those of Nd.
\end{abstract}

Keywords: solvent extraction; magnet scrap; ionic liquid; extractant

\section{Introduction}

Rare earth metals play an important role in advanced materials such as permanent magnets, catalysts, batteries, and glass. However, the availability of rare earth metals is sometimes critical due to geopolitical issues. Therefore, there is a need to develop a sustainable and economically feasible recycling process for the recovery of rare earth metals from secondary sources to reduce the dependency of the rare earth metal supply on mining production. In secondary sources, neodymium magnets contain a high percentage of rare earth metals (typically $25 \% \mathrm{Nd}$ ) [1]. A small amount of Dy (1\%) and $\mathrm{Ni}(2 \%)$ are included to increase temperature stability against demagnetization and to prevent corrosion, respectively. Rare earth metals from the neodymium magnets have been recovered by a hydrometallurgical method consisting of leaching, solvent extraction, and precipitation [2]. After acid leaching, a solvent extraction technique is applied to separate the rare earth metals from the leach liquor. Many extractants have been studied for rare earth metal extraction and separation [3]. Even since 2017, many studies have been reported using conventional extractants such as bis(2-ethylhexyl) phosphoric acid [4-6], CYANEX 302 (bis(2,4,4-trimethylpentyl) monothiophosphinic acid [7], carboxylic acid [8], $N, N, N^{\prime}, N^{\prime}$-tetraoctyl-diglycolamide (TODGA) [1,9] and quaternary ammonium salts (a type of ionic liquid) [10]. Bifunctional ionic liquid extractants composed of a quaternary ammonium cation and a phosphonic acid or carboxylic acid anion were developed for rare earth metal extraction and separation [11]. These extractants have high extractability, but must be synthesized via several steps. Recently, interest has focused on hydrophobic protic ionic liquid, which can be simply prepared by mixing amine and acid, as an extractant. Palladium, platinum, and gallium extraction with protic ionic liquid, trioctylammonium nitrate, diluted in trioctylammonium bis(trifluoromethanesulfonyl)amide [TOAH] $\left[\mathrm{NTf}_{2}\right][12,13]$, copper extraction with protic ionic liquids composed of alkylamine and aliphatic carboxylic acid [14], and neodymium extraction with protic ionic liquid composed of Primene 81-R 
(primary amine) and CYANEX 572 (organophosphorus acidic compound) diluted in kerosene [15] have been reported. However, the equimolar mixtures of acids and bases has properties suggesting that proton transfer does not occur based on pKa values and other physical measurements [16]. Therefore, such mixtures are now referred to as pseudoprotic ionic liquids. In this study, we examined the extraction properties of $\mathrm{Nd}, \mathrm{Dy}$, and $\mathrm{Ni}$ with a pseudoprotic ionic liquid composed of trioctylamine and decanoic acid without diluent. It is desirable to avoid the use of organic diluents to reduce the environmental load.

\section{Materials and Methods}

The decanoic acid and trioctylamine used as ionic liquid constituents were purchased from Wako Pure Chemical Industries, Ltd. and used as received. For the preparation of the ionic liquid, we placed $0.1 \mathrm{~mol} / \mathrm{dm}^{3}$ of decanoic acid and trioctylamine in a $300 \mathrm{~mL}$ Erlenmeyer flask and stirred for $4 \mathrm{~h}$ using a magnetic stirrer at room temperature. The decanoic acid was heated to liquification before mixing. The mixtures formed a clear liquid at room temperature. Viscosity was measured by a capillary viscometer. Nickel chloride, neodymium chloride, and dysprosium chloride were purchased from NacalaiTesque, Inc., Kyoto, Japan. All other chemicals were used without further purification.

The aqueous solution was prepared by dissolving $5 \mathrm{mmol} / \mathrm{dm}^{3}$ of metal solution in various concentrations of hydrochloric acid, nitric acid, sodium chloride, and sodium nitrate. Equal volumes $\left(2 \mathrm{~cm}^{3}\right)$ of the aqueous solution and ionic liquid were mixed and shaken $(120 \mathrm{rpm})$ in a thermostat water bath at $303 \mathrm{~K}$. After shaking for $12 \mathrm{~h}$ to attain equilibrium, the concentration of metal in the aqueous phase was measured using inductively coupled plasma atomic emission spectroscopy (ICP-AES, ICPS-8100, Shimadzu, Kyoto, Japan). The detection limits for Nd, Dy, and Ni are 2, 1, and $5 \mu \mathrm{g} / \mathrm{dm}^{3}$, respectively. The percentage of extraction and distribution ratio, $D$, were calculated using Equations (1) and (2).

$$
\begin{aligned}
& \% \text { Extraction }=\frac{[\mathrm{M}]_{\mathrm{IL} \cdot \mathrm{eq}}}{[\mathrm{M}]_{\mathrm{aq} \cdot \mathrm{int}}} \times 100=\frac{[\mathrm{M}]_{\mathrm{aq} \cdot \operatorname{int}}-[\mathrm{M}]_{\mathrm{aq} \cdot \mathrm{eq}}}{[\mathrm{M}]_{\mathrm{aq} \cdot \mathrm{int}}} \times 100 \\
& D=\frac{[M]_{\text {aq.int }}-[M]_{\text {aq.eq }}}{[M]_{\text {aq.eq }}}
\end{aligned}
$$

where $[\mathrm{M}]_{\mathrm{IL} . e q}$ and $[\mathrm{M}]_{\text {aq.eq }}$ are the equilibrium concentration of metal in the ionic liquid and aqueous phase, respectively, and $[\mathrm{M}]_{\mathrm{aq} . \text { int }}$ is the initial metal concentration in the aqueous phase. The values obtained were averaged over three measurements.

The separation factor, $\beta$, between two metals was defined as Equation (3)

$$
\beta=\frac{D_{1}}{D_{2}}
$$

where $D_{1}$, and $D_{2}$ are the distribution ratios $D$ of metal 1 and metal 2 , respectively.

\section{Results}

Usually, the high viscosity of ionic liquids is a problem in the solvent extraction process. Viscosities were reported to be $274.2 \mathrm{mPa} \cdot \mathrm{s}$ for [TOAH] [NTf 2 ] at $25^{\circ} \mathrm{C}$ [12] and $95 \mathrm{mPa} \cdot \mathrm{s}$ for water- saturated CYPHOS IL101 at $60^{\circ} \mathrm{C}$ [17]. The viscosity of the present pseudoprotic ionic liquid composed of trioctylamine and decanoic acid is $9.1 \mathrm{mPa} \cdot \mathrm{s}$. This value is very low for ionic liquids and is suitable for use as a solvent in a two-phase extraction system.

\subsection{Extraction of Metal Ions from Aqueous Acid Solutions}

In most cases, hydrochloric acid [18] and nitric acid [19] have been used as the leaching agent from scrap magnets. In this work, we first investigated the effect of the hydrochloric acid concentration on the extractability of metal ions, including $\mathrm{Nd}$ (III), Dy (III), and Ni (II), the results of which are shown in Figure 1. Unfortunately, the addition of a small amount of hydrochloric acid caused a rapid decrease in the extractabilities of all metal ions. The pseudoprotic ionic liquid $\left(\mathrm{R}_{3} \mathrm{NH}^{+} \mathrm{R}^{\prime} \mathrm{COO}^{-}\right)$ 
contacted with hydrochloric acid was converted to quaternary ammonium chloride $\left(\mathrm{R}_{3} \mathrm{NH}^{+} \mathrm{Cl}^{-}\right)$by the following equation.

$$
\mathrm{R}_{3} \mathrm{NH}^{+} \mathrm{R}^{\prime} \mathrm{COO}_{\mathrm{IL}}^{-}+\mathrm{HCl}_{\mathrm{aq}} \rightleftharpoons \mathrm{R}_{3} \mathrm{NH}^{+} \mathrm{Cl}_{\mathrm{IL}}^{-}+\mathrm{R}^{\prime} \mathrm{COOH}_{\mathrm{IL}}
$$

Figure 1 suggests that this quaternary ammonium chloride does not function well as a metal extractant. Therefore, we examined the effect of the nitric acid concentration as shown in Figure 2. Evidently, at a high nitric acid concentration $\left(1.0 \mathrm{~mol} \mathrm{dm}^{-3}\right)$, the ionic liquid lost its metal extractability due to the formation of quaternary ammonium nitrate $\left(\mathrm{R}_{3} \mathrm{NH}^{+} \mathrm{NO}_{3}{ }^{-}\right)$. However, the degree of decline of the extractability with increasing nitric acid concentration is smaller than that with hydrochloric acid. Extractability of nitric acid with trioctylamine diluted in benzene was higher than that of hydrochloric acid [20]. Therefore, the higher extractabilities of metal ions in the nitric acid solution was due to the nitrate ions which are easily co-extracted with the metal cation $\left(\mathrm{M}^{\mathrm{n}+}\right)$ due to their more chaotropic character compared to chloride anion, allowing a neutral extractive species in the ionic liquid phase $\left(\mathrm{M}\left(\mathrm{NO}_{3}\right)_{\mathrm{n}}\right)$. In the low concentration nitric acid solution, the rare earth metals were selectively extracted to the ionic liquid phase. Because their extractabilities were not very high, we examined the effect of salts to obtain better efficiency.

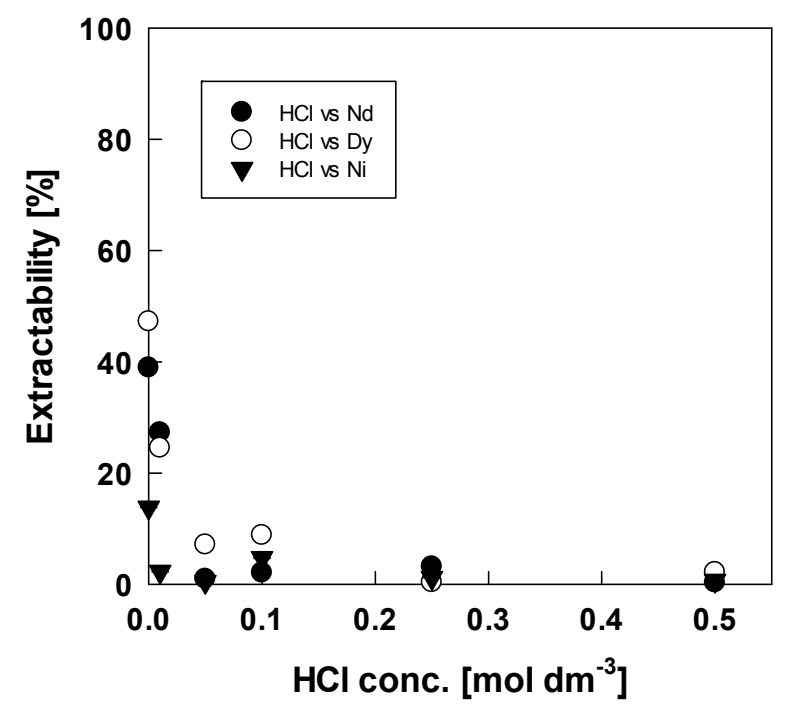

Figure 1. Effect of $\mathrm{HCl}$ concentration on metal extractability.

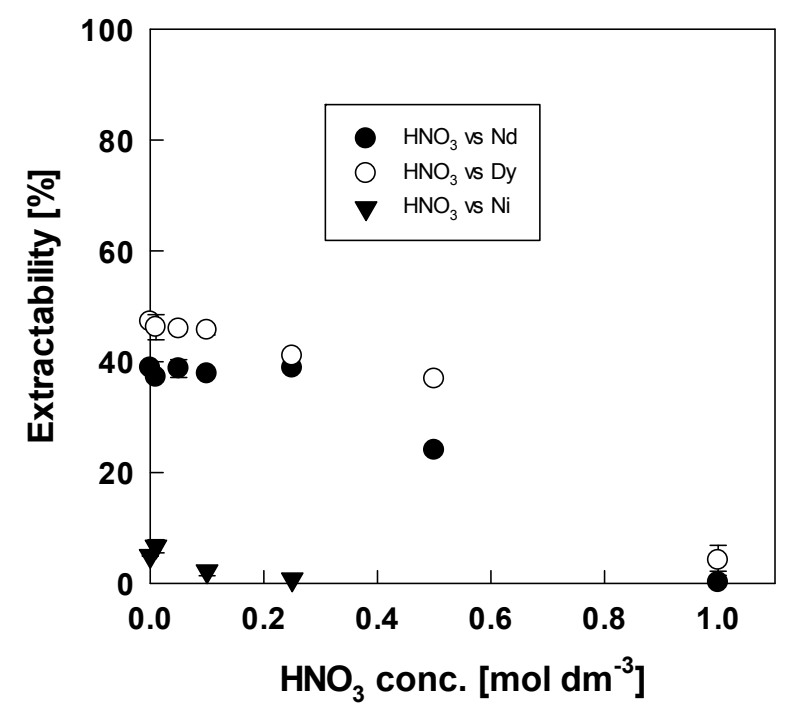

Figure 2. Effect of $\mathrm{HNO}_{3}$ concentration on metal extractability. 


\subsection{Effect of Salts on Metal Extractability}

The positive effect of the salts, sodium chloride and sodium nitrate, on the extractions of rare earth metals with bifunctional ionic liquids has been documented [11]. Figures 3 and 4 show the effects of sodium chloride and sodium nitrate on the metal extraction. The extractabilities increased with increasing salt concentrations of all metal ions. The rare earth metals were found to be preferentially extracted compared to nickel ion. The rare earth metal concentrations in the raffinates were below the detection limit by ICP with the above concentrations of $1.0 \mathrm{~mol} \mathrm{dm}^{-3} \mathrm{NaCl}$ and $0.05 \mathrm{~mol} \mathrm{dm}^{-3} \mathrm{NaNO}_{3}$. Sodium nitrate was more effective for the extractability than sodium chloridebecause nitrate anion has a more chaotropic character than chloride anion. This result is consistent with the extractions of copper with a pseudoprotic ionic liquid [14] and of rare earth metals with a bifunctional ionic liquid extractant [11]. The Nd and nitrate in the ionic liquid (1-butyl-3- methylimidazolium bis(trifluoromethylsulfonyl)imide) was reported to form much stronger complexes [21]. From the present result and previous studies [1,5], we developed the following equations based on the ion association mechanism between metal salts and neutral pseudoprotic ionic liquid and the complexation between metal cations $\left(\mathrm{M}^{\mathrm{n}+}\right)$ and the carboxylate groups on the pseudoprotic ionic liquid in the presence of salts (NaX).

$$
\begin{gathered}
\mathrm{M}_{\mathrm{aq}}^{\mathrm{n}+}+\mathrm{nX}_{\mathrm{aq}}^{-}+\mathrm{mR}_{3} \mathrm{NH}^{+} \mathrm{R}^{\prime} \mathrm{COO}_{\mathrm{IL}}^{-} \rightleftharpoons \mathrm{MX}_{\mathrm{n}} \mathrm{mR}_{3} \mathrm{NH}^{+} \mathrm{R}^{\prime} \mathrm{COO}_{\mathrm{IL}}^{-} \\
\mathrm{M}_{\mathrm{aq}}^{\mathrm{n}+}+\mathrm{nX}_{\mathrm{aq}}^{-}+\mathrm{nR}_{3} \mathrm{NH}^{+} \mathrm{R}^{\prime} \mathrm{COO}_{\mathrm{IL}}^{-} \rightleftharpoons \mathrm{M}(\mathrm{RCOO})_{\mathrm{n}, \mathrm{IL}}+\mathrm{nR}_{3} \mathrm{NH}^{+} X_{\mathrm{IL}}^{-}
\end{gathered}
$$

where $\mathrm{X}$ is $\mathrm{Cl}$ or $\mathrm{NO}_{3}$, and $\mathrm{n}$ and $\mathrm{m}$ are the valency of the metal ion and solvation number, respectively.

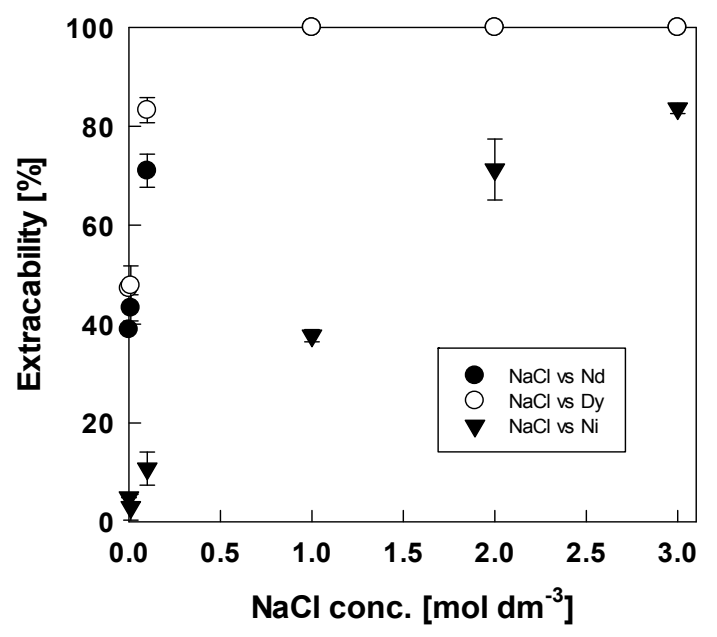

Figure 3. Effect of $\mathrm{NaCl}$ concentration on metal extractability.

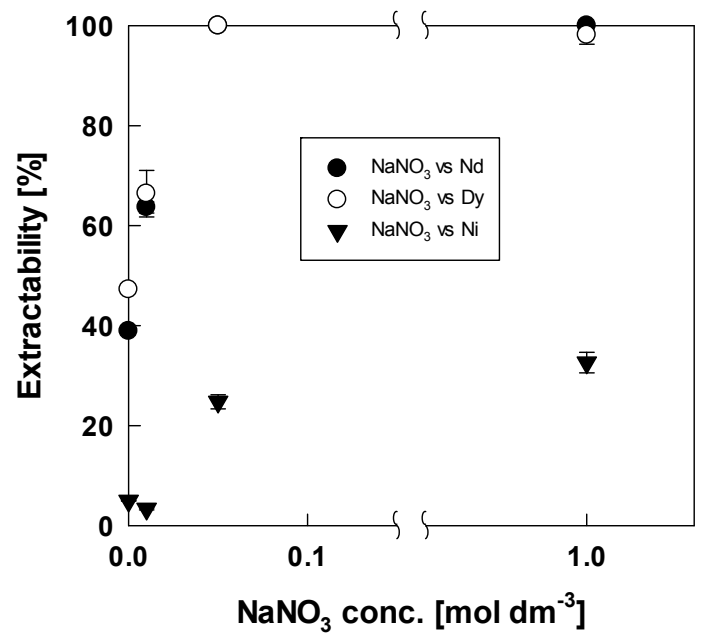

Figure 4. Effect of $\mathrm{NaNO}_{3}$ concentration on metal extractability. 
The separation factors, $\beta$, of metal extraction in chloride and nitrate media are shown in Tables 1 and 2 , respectively. These tables indicate that rare earth metals could be separated from nickel and the $\beta$ values between nickel and rare earth metals in the nitrate medium are higher than those in chloride media. The distribution ratios of Dy were higher than those of $\mathrm{Nd}$ in both media as with bifunctional ionic liquids in biosolvent $(\beta=1.24,1.53)$ [22]. However, the result is the opposite for extractions with tri-n-octylmethylammonium nitrate in xylene $(\beta=0.17)$ [23] and neodecanoic acid in kerosene $(\beta=0.13)$ [8]. This may be caused by the difference in the extraction mechanism: an ion association mechanism for pseudoprotic ionic liquid and an ion exchange mechanism for ammonium salt and carboxylic acid. Although separation factors in this study are smaller than those of bifunctional ionic liquids, the pseudoprotic ionic liquid extractant had the advantages of no diluent and relatively low viscosity $(9.1 \mathrm{mPa} \cdot \mathrm{s})$. Therefore, the effects of a constituted species of alkylamine and aliphatic carboxylic acid, and salts will be examined to enhance selectivity. At present, the hydrophobic pseudoprotic ionic liquid used in this study could be applied for the coarse separation of a transition metal and rare earth metals required to be recovered.

Table 1. Separation factor $\left(\beta=D_{1} / D_{2}\right)$ in chloride media $\left(\mathrm{NaCl} 0.01 \mathrm{~mol} \mathrm{~L}^{-1}\right)$.

\begin{tabular}{|c|c|c|}
\hline$D_{2}^{D_{1}}$ & Nd & Dy \\
\hline $\mathrm{Ni}$ & 25.1 & 30.1 \\
\hline $\mathrm{Nd}$ & - & 1.12 \\
\hline
\end{tabular}

Table 2. Separation factor $\left(\beta=D_{1} / D_{2}\right)$ in nitrate media $\left(\mathrm{NaNO}_{3} 0.01 \mathrm{~mol} \mathrm{~L}^{-1}\right)$.

\begin{tabular}{|c|c|c|}
\hline$D_{D_{2}} D_{1}$ & $\mathrm{Nd}$ & Dy \\
\hline $\mathrm{Ni}$ & 50.6 & 57.1 \\
\hline $\mathrm{Nd}$ & - & 1.13 \\
\hline
\end{tabular}

\section{Conclusions}

In this work, we used an undiluted hydrophobic pseudoprotic ionic liquid composed of trioctylamine and decanoic acid, as an extractant to separate the rare earth metals (Dy and $\mathrm{Nd}$ ) from aqueous media by a solvent extraction technique. In the acidic media, the extractabilities decreased with increase in the acid concentrations because of the anion exchange reaction between decanoate and chloride or nitrate. In the presence of salts like sodium chloride and sodium nitrate, the extractabilities of Dy and $\mathrm{Nd}$ reached $100 \%$. An ion association involving $\mathrm{MX}_{\mathrm{n}}$ as the extracted species and the complexation between carboxylate and metal cation were deduced as the extraction mechanisms. Under all experimental conditions, the rare earth metals (Dy and $\mathrm{Nd}$ ) were found to be preferentially extracted compared to nickel and the distribution ratios of Dy were higher than those of $\mathrm{Nd}$. In this paper, we established that an undiluted hydrophobic pseudoprotic ionic liquid with a relatively low viscosity has the potential to separate rare earth metals.

Author Contributions: Conceptualization, M.M.; methodology, M.M.; validation, M.M., T.Y. and Y.T.; formal analysis, T.Y.; investigation, T.Y.; data curation, Y.T.; writing—original draft preparation, M.M.; writing-review and editing, M.M; All authors have read and agreed to the published version of the manuscript.

Funding: This research received no external funding

Conflicts of Interest: The authors declare no conflict of interest.

\section{References}

1. Gergoric, M.; Ekberg, C.; Foreman, M.R.; Steenari, B.; Retegan, T. Characterization and leaching of neodymium magnet waste and solvent extraction of the rare-earth elements using TODGA. J. Sustainable Metall. 2017, 3, 638-645. [CrossRef]

2. Ferron, C.J.; Henry, R. A review of the recycling of rare earth metals. Can. Metall. Q. 2015, 54, 388-394. [CrossRef] 
3. Ismail, N.A.; Aziz, M.A.A.; Yunus, M.Y.M.; Hisyam, A. Selection of extractant in rare earth solvent extraction system: A review. Int. J. Recent. Technol. Eng. 2019, 8, 728-742.

4. Gergoric, M.; Ravaux, C.; Steenari, B.; Espegren, F.; Retegan, T. Leaching and recovery of rare-earth elements from neodymium magnet waste using organic acid. Metals 2018, 8, 721. [CrossRef]

5. Gergoric, M.; Barrieri, A.; Retegan, T. Recovery of rare-earth elements from neodymium magnet waste using glycolic, maleic, and ascorbic acids followed by solvent extraction. J. Sustainable Metall. 2019, 5, 85-96. [CrossRef]

6. Mi'am, A.C.; Wang, Y.; Chen, S.; Chang, G.; You, S. Simultaneous recovery of rare earth elements from waste permanent magnets (WPMs) leach liquor by solvent extraction and hollow fiber supported liquid membrane. Chem. Eng. Process. 2020, 148, 107831.

7. Padha, E.; Nayak, A.K.; Sarangi, K. Recovery of neodymium and dysprosium from NdFeB magnet swarf. Hydrometallurgy 2017, 174, 210-215. [CrossRef]

8. Habaki, H.; Nakamura, K.; Egashira, R. Extraction equilibria of valuable metals from NdFeB permanent magnet using carboxylic acid as extractant. J. Chem. Eng. Jpn. 2017, 50, 610-617. [CrossRef]

9. Deshmane, V.G.; Islam, S.Z.; Bhave, R.R. Selective recovery of rare earth elements from a wide range of E-waste and process scalability of membrane solvent extraction. Environ. Sci. Technol. 2020, 54, 550-558. [CrossRef]

10. Kumari, A.; Sahu, K.K.; Sahu, S.K. Solvent extraction and separation of Nd, Pr and Gy from leach liquor of waste $\mathrm{NdFeB}$ magnet using the nitrate form of Mextral33At in the presence of aquo-complexing agent EDTA. Metals 2019, 9, 269. [CrossRef]

11. Guo, L.; Chen, J.; Shen, L.; Zhang, J.; Zhang, D.; Deng, Y. Highly selective extraction of rare earth (III) using bifunctional ionic liquid extractant. ACS Sustainable Chem. Eng. 2014, 2, 1968. [CrossRef]

12. Katsuta, S.; Yoshimoto, Y.; Okai, M.; Takeda, Y.; Bessho, K. Selective extraction of palladium and platinum from hydrochloric acid solutions by trioctylammonium-based mixed ionic liquids. Ind. Eng. Chem. Res. 2011, 50, 12735-12740. [CrossRef]

13. Katsuta, S.; Okai, M.; Yoshimoto, Y.; Kudo, Y. Extraction of gallium (III) from hydrochloric acid solutions by trioctylammonium-based mixed ionic liquids. Anal. Sci. 2012, 28, 1009-1012. [CrossRef] [PubMed]

14. Janssen, C.H.C.; Macías-Ruvalcava, N.A.; Aguilar-Martínez, M.; Kobrak, M.N. Copper extraction using protic ionic liquids: Evidence of the Hofmeister effect. Sep. Purif. Technol. 2016, 168, 275-283. [CrossRef]

15. Pavón, S.; Fortuny, A.; Coll, M.T.; Sastre, A.M. Neodymium recovery from NdFeB magnet wastes using Primene81R-Cyanex 572 IL by solvent extraction. J. Environ. Manage. 2018, 222, 259-367. [CrossRef]

16. Patsos, N.; Lewis, K.; Picchioni, F.; Kobrak, M.N. Extraction of acids and bases from aqueous phase to a pseudoprotic ionic liquid. Molecules 2019, 24, 894. [CrossRef]

17. Hoogerstraete, T.V.; Wellens, S.; Verachtert, K.; Binnemans, K. Removal of transition metals from rare earths by solvent extraction with an undiluted phosphonium ionic liquid: Separations relevant to rare-earth magnet recycling. Green Chem. 2013, 15, 919-927. [CrossRef]

18. Lee, C.; Chen, Y.; Liao., C.; Popuri, S.R.; Tsai, S.; Hung, C. Selective leaching process for neodymium recovery from scrap Nd-Fe-B magnet. Metall. Mater. Trans. 2013, 44, 5825-5833. [CrossRef]

19. Önal, M.A.R.; Atkan, E.; Borra, C.R.; Blanpain, B.; van Gerven, T.; Guo, M. Recycling of NdFeB magnets using nitration, calcination and water leaching for REE recovery. Hydrometallurgy 2017, 167, 115-123. [CrossRef]

20. Sato, T. Extraction of some mineral acids by tri-n-octylamine. J. Appl. Chem. 1965, 15, 10-16. [CrossRef]

21. Liu, L.; Tian, G.; Rao, L. Effect of solvation? Complexation of neodymium (III) with nitrate in an ionic liquid $\left(\mathrm{BUMIMTF}_{2} \mathrm{~N}\right)$ in comparison with nitrate. Solvent Extr. Ion Exch. 2013, 31, 384-400. [CrossRef]

22. Wang, W.; Yang, H.; Cui, H.; Zhang, D.; Liu, Y.; Chen, J. Application of bifunctional ionic liquid extractants [A336][CA-12] and [A336][CA-100] to the lanthanum extraction and separation from rare earths in the chloride media. Ind. Eng. Chem. Res. 2011, 50, 7534-7541. [CrossRef]

23. Komasawa, I.; Hisada, K.; Miyamura, M. Extraction and separation of rare-earth elements by tri-n-octylmethylammonium nitrate. J. Chem. Eng. Jpn. 1990, 23, 308-315. [CrossRef]

(C) 2020 by the authors. Licensee MDPI, Basel, Switzerland. This article is an open access article distributed under the terms and conditions of the Creative Commons Attribution (CC BY) license (http://creativecommons.org/licenses/by/4.0/). 